\section{FRI0366 PRIMARY RESPIRATORY DISEASE IN PATIENTS WITH SYSTEMIC LUPUS ERYTHEMATOSUS: DATA FROM THE SPANISH RHEUMATOLOGY SOCIETY LUPUS REGISTRY (RELESSER) COHORT}

J. Narvaez ${ }^{1}$, H. Borrell ${ }^{1}$, F. Sánchez-Alonso ${ }^{2}$, I. Rúa-Figueroa ${ }^{3}$, F.J. Lopez-Longo ${ }^{4}$, M. Galindo ${ }^{5}$, J. Calvo-Alen ${ }^{6}$, A. Fernández-Nebro ${ }^{7}$, A. Olivé ${ }^{8}$, J.L. Andreu ${ }^{9}$, R. Blanco ${ }^{10}, M$. Andres ${ }^{11}$, J.J. Alegre ${ }^{12}$, T. Cobo-lbañez ${ }^{13}$, G. Bonilla $^{14}$, A. Boteanu ${ }^{15}$, E. Díez-Álvarez ${ }^{16}, M$. Freire ${ }^{17}, M$. Gantes $^{18}$, P. Garcia de la Peña ${ }^{19}$, R. Garcia-Vicuña ${ }^{20}$, J. Hernández Beiraín ${ }^{21}$, M.L. Horcada ${ }^{22}$, J. lbañez ${ }^{23}$, A. Juan $\mathrm{Mas}^{24}$, N. Lozano-Rivas ${ }^{25}$, J.L. Marenco ${ }^{26}$, I. Castelvi2 ${ }^{27}$, C. Montilla-Morales ${ }^{28}$, M. Moreno ${ }^{29}$, A. Pecondon-Españo ${ }^{30}$, E. Ruiz Lucea ${ }^{31}$, A. Sanchez-Atrio ${ }^{32}$, G. Santos-Soler ${ }^{33}$, F. Toyos ${ }^{34}$, E. Uriarte Isacelaya ${ }^{35}$, T.R. Vazquez-Rodriguez ${ }^{36}$, J.M. Nolla ${ }^{1}$, J.M. Pego-Reigosa ${ }^{37}$ on behalf of EAS-SER (Systemic Diseases Study Group of the Spanish Society of Rheumatology). ${ }^{1}$ Rheumatology, Hospital Universitario de Bellvitge, Hospitalet de LLobregat, Barcelona; ${ }^{2}$ Unidad de Investigacion, Sociedad Española de Reumatologia, Madrid; ${ }^{3}$ Rheumatology, Hospital Universitario Doctor Negrin, Las Palmas de Gran Canaria; ${ }^{4}$ Rheumatology, Hospital Universitario Gregorio Marañón; ${ }^{5}$ Rheumatology, Hospital Universitario 12 de octubre, Madrid; ${ }^{6}$ Rheumatology, Hospital Universitario Araba, Vitoria; ${ }^{7}$ Rheumatology, Hospital Universitario de Málaga., Malaga; ${ }^{8}$ Rheumatology, Hospital Germans Trias i Pujol, Badalona. Barcelona; ${ }^{9}$ Rheumatology, Hospital Universitario Puerta de Hierro, Madrid; ${ }^{10}$ Rheumatology, Hospital Universitario Marqués de Valdecilla, Santander, ${ }^{11}$ Rheumatology, Hospital General Universitario de Alicante., Alicante; ${ }^{12}$ Rheumatology, Hospital Universitario Dr Peset, Valencia: ${ }^{13}$ Rheumatology, Hospital Universitario Reina Sofía;

${ }^{14}$ Rheumatology, Hospital Universitario La Paz; ${ }^{15}$ Rheumatology, Hospital Universitario Ramon y Cajal, Madrid; ${ }^{16}$ Rheumatology, Complejo Asistencial Universitario de León, Leon; ${ }^{17}$ Rheumatology, Complexo Hospitalario Universitario de A Coruña, La Coruña; ${ }^{18}$ Rheumatology, Hospital Universitario de Canarias, Tenerife; ${ }^{19}$ Rheumatology, Hospital Madrid Norte Sanchinarro; ${ }^{20}$ Rheumatology, Hospital Universitario de La Princesa, Madrid; ${ }^{21}$ Rheumatology, Hospital Insular de Gran Canaria, Las Palmas de Gran Canaria; ${ }^{22}$ Rheumatology, Hospital de Navarra, Pamplona; ${ }^{23}$ Rheumatology, Hospital Povisa, Vigo; ${ }^{24}$ Rheumatology, Hospital Son LLatzer, Mallorca; ${ }^{25}$ Rheumatology, Hospital Virgen de la Arrixaca, Murcia; ${ }^{26}$ Rheumatology, Hospital de Valme, Sevilla; ${ }^{27}$ Rheumatology, Hospital de Sant Pau, Barcelona; ${ }^{28}$ Rheumatology, Hospital Clínico Universitario de Salamanca, Salamanca; ${ }^{29}$ Rheumatology, Hospital Parc Taulí, Sabadell, Barcelona; ${ }^{30}$ Rheumatology, Hospital Miguel Servet, Zaragoza; ${ }^{31}$ Rheumatology, Hospital de Basurto, Billbao; ${ }^{32}$ Rheumatology, Hospital Universitario Príncipe de Asturias, Alcalá de Henares. Madrid; ${ }^{33}$ Rheumatology, Hospital Marina Baixa, Villajoyosa. Alicante; ${ }^{34}$ Rheumatology, Hospital Universitario Virgen de la Macarena, Sevilla; ${ }^{35}$ Rheumatology, Hospital Universitario de Donosti, San Sebastián; ${ }^{36}$ Rheumatology, Hospital Universitario Lucus Augusti, Lugo;

${ }^{37}$ Rheumatology, Complexo Hospitalario Universitario de Vigo, Vigo, Spain

Objectives: To investigate the primary respiratory manifestations (PRM) in SLE. Methods: All patients in the RELESSER cohort were retrospectively investigated for the presence of PRM

Results: At least one PRM was present in 11.3\% (365/3215) of cases. The most common was pleurisy, occurring in $21.1 \%$ of patients, followed by ALP in $3.6 \%$, PE in $2.9 \%$, PPH $4 \%$, DILD in $2 \%$, DAH in $0.8 \%$, and SLS in $0.8 \%$.

The variables associated with the presence of PPM are shown in the following table 1:

\begin{tabular}{lccc}
\hline & $\begin{array}{c}\text { Odds } \\
\text { Ratio }\end{array}$ & $\begin{array}{c}95 \% \\
\text { Confidence } \\
\text { Interval }\end{array}$ & $P$ \\
\hline Age & 1,03 & $1,02-1,04$ & 0.000 \\
SLEDAI score & 1,03 & $1,00-1,07$ & 0,02 \\
Raynaud phenomenon & 1,41 & $1,09-1,84$ & 0,01 \\
Severe nephritis & 1,56 & $1,18-2,06$ & 0002 \\
Secondary APS & 2,2 & $1,63-2,97$ & 0.000 \\
Anti-RNP positivity & 1,32 & $1,00-1,75$ & 0054 \\
Cardiac disease & 2,81 & $1,90-4,16$ & 0000 \\
Vasculitis & 1,81 & $1,25-2,62$ & 0002 \\
Hematologic abnormalities & 1,31 & $1,00-1,71$ & 0048 \\
Neuropsychiatric & 1,49 & $1,11-2.02$ & 0009 \\
manifestations & 2,05 & $1,14-3,67$ & 0016 \\
Gastrointestinal involvement & multivariable model, PPM remained a risk
\end{tabular}

After adjusting for known confounders in the multivariable model, PPM remained a risk

factor for diminished survival (HR: 3.13).

Conclusions: PPM independently contributed to a decreased survival in SLE Disclosure of Interest: None declared

DOI: 10.1136/annrheumdis-2018-eular.6436

\section{FRI0367 \\ ASSOCIATION OF VITALITY AND SUBSEQUENT PHYSICAL FUNCTIONING IN SYSTEMIC LUPUS ERYTHEMATOSUS: ANALYSIS OF DATA FROM THE GERMAN LULA COHORT $2002-2013$}

J. Mucke $^{1}$, G. Chehab ${ }^{1}$, R. Fischer-Betz ${ }^{1}$, J. Richter ${ }^{1}$, B. Winkler-Rohlfing ${ }^{2}$, M. Schneider ${ }^{1}$, R. Brinks ${ }^{1} .{ }^{1}$ Policlinic of Rheumatology and Hiller-Research Centre of Rheumatology, Heinrich-Heine-University Duesseldorf, Düsseldorf, ${ }^{2}$ German Lupus Self-Help Community, Wuppertal, Germany

Background: Fatigue, defined as loss of vitality, is a major burden in patients with systemic lupus erythematosus (SLE). It is well-known from cross-sectiona studies that fatigue is associated with physical functioning (PF) whereas the effect of fatigue on subsequent PF has not yet been further looked on.

Methods: Data from the German Lupus-Langzeitstudie (LuLa) cohort was used to explore the effect of self-reported vitality on PF. The ongoing LuLa study com prises patients from the German SLE self-help group. The current analysis uses data from 2002 to 2013. We looked for associations between the PF score (outcome) and the vitality score of the SF-12 questionnaire in one to four years preceding the outcome. Statistical analysis was accomplished by a linear mixed regression model (LMM) adjusting for the potential confounders age, sex, disease duration and disease activity as surveyed by the Systemic Lupus Activity Questionnaire score (SLAQ).

Results: 1511 patients (93.3\% women) provided data with a total of 7841 personyears of observation. Median age at study entry was 46 (interquartile range: 37 to 57). The table 1 shows the regression coefficients of the vitality score (and 95\% confidence intervals, $\mathrm{Cl}$ ) estimated by the LMM without and with adjusting for age sex, disease duration and SLAQ.

\begin{tabular}{lcccc}
\hline $\begin{array}{l}\text { Exposure: Vitality scale } \\
\text { score }\end{array}$ & \multicolumn{2}{c}{ Crude estimates } & \multicolumn{2}{c}{ Adjusted estimates } \\
\cline { 2 - 5 } & $\begin{array}{l}\text { Estimate with } \\
95 \% \mathrm{Cl}\end{array}$ & $\mathrm{p}$-value & $\begin{array}{c}\text { Estimate with } \\
95 \% \mathrm{Cl}\end{array}$ & $\mathrm{p}$-value \\
\hline 1 year ahead & $0.08(0.05-0.10)$ & $<0.001$ & $0.07(0.05-0.09)$ & $<0.001$ \\
2 years ahead & $0.09(0.07-0.11)$ & $<0.001$ & $0.07(0.05-0.09)$ & $<0.001$ \\
3 years ahead & $0.05(0.03-0.08)$ & $<0.001$ & $0.05(0.03-0.07)$ & $<0.001$ \\
4 years ahead & $0.03(0.001-0.06)$ & 0.038 & $0.04(0.01-0.07)$ & 0.002 \\
\hline
\end{tabular}

Conclusions: We found evidence that self-reported vitality in patients with SLE is associated with PF in the subsequent years. The data indicate a "window of opportunity" for treating fatigue symptoms of up to four years for maintenance of PF.

Disclosure of Interest: J. Mucke: None declared, G. Chehab Grant/research support from: GlaxoSmithKline and UCB Pharma for performing the LuLa-study, R. Fischer-Betz Grant/research support from: GlaxoSmithKline and UCB Pharma for performing the LuLa-study, J. Richter Grant/research support from: GlaxoSmithKline and UCB Pharma for performing the LuLa-study, B. Winkler-Rohlfing: None declared, M. Schneider Grant/research support from: GlaxoSmithKline and UCB Pharma for performing the LuLa-study, R. Brinks: None declared DOI: 10.1136/annrheumdis-2018-eular.4889

\section{FRI0368 COMPARISON OF CLINICAL AND LABORATORY PROFILES IN 3575 SYSTEMIC LUPUS ERYTHEMATOSUS PATIENTS WITH AND WITHOUT SJÖGREN'S SYNDROME: DATA FROM A NATIONWIDE PATIENT REGISTRY (RELESSER)}

J.G. Ovalles-Bonilla ${ }^{1}$, F.J. López-Longo ${ }^{1}$, I. Rúa-Figueroa ${ }^{2}$, M. Galindo ${ }^{3}$, J. CalvoAlen $^{4}$, R.D. González ${ }^{1}$, B. Serrano ${ }^{1}$, I. Janta ${ }^{5}$, C. González ${ }^{5}$, I. Monteagudo ${ }^{5}$, J. C. Nieto ${ }^{5}$, J. Martínez ${ }^{5}$, C.N. Saenz ${ }^{5}$, J.M. Pego-Reigosa ${ }^{6}$, on behalf of RELESSER. ${ }^{1}$ Rheumatology, Hospital General Universitario Gregorio Marañón, Madrid; ${ }^{2}$ Rheumatology Division, Hospital Doctor Negrin, Las Palmas GC;

${ }^{3}$ Servicio de Reumatología, Hospital 12 de Octubre, Madrid; ${ }^{4}$ Rheumatology, Txagorritxu Hospital, Araba, Vitoria; ${ }^{5}$ Rheumatology, Hospital General Universitario Gregorio Marañón, Madrid; ${ }^{6}$ Rheumatology Section, Hospital de Meixoeiro, Pontevedra, Vigo, Spain

Background: The clinical coexistence of Systemic Lupus Erythematosus (SLE) and Sjögren's Syndrome (SS) was recognised in 1959. The prevalence of SS among patients with SLE varies considerably among the published studies $(10 \%-$ $30 \%$ ). There is still controversy as to whether or not SLE patients with overlapping SS have a distinct and significantly milder lupus.

Objectives: To address the clinical and serologic features of SLE and differences from SLE that occurs in overlap with SS.

Methods: A retrospective cohort of 3575 unselected SLE patients from 45 Rheumatology Units across Spain was evaluated for the presence of overlapping SS 